\title{
Glutamate dysfunction in Alzheimer's disease: an hypothesis
}

\author{
William F. Maragos, J. Timothy Greenamyre, John B. Penney, Jr \\ and Anne B. Young
}

Glutamate is a major excitatory neurotransmitter that has been implicated in memory formation and learning. This acidic amino acid also has neurotoxic properties, and in animals produces lesions reminiscent of human neurodegenerative diseases. Here we present evidence that supports the hypothesis that glutamate dysfunction is involved in the pathophysiology of Alzheimer's disease and can account for many of the neurochemical and behavioral deficits observed in this disease.

Dementia of the Alzheimer type (DAT) is a debilitating neurological disease that affects about one in six individuals past the age of sixty ${ }^{1,2}$. Its etiology is unknown. Patients with DAT suffer severe memory loss, personality changes, and symptoms of cortical disconnection: apraxias, aphasias and agnosias $^{3-5}$. The pathological changes in DAT brains include the presence of senile plaques, neurofibrillary tangles and granulovacuolar degeneration in cerebral cortex, amygdala, olfactory tubercle and hippocampus ${ }^{6-8}$. Neurochemical studies indicate alterations in the cholinergic ${ }^{9,10}$, somatostatinergic $^{11,12}$, serotonergic ${ }^{13-15}$ noradrenergic ${ }^{16,17}$ and glutamatergic systems ${ }^{18-21}$. The numerous hypotheses concerning the etiology of this disorder include abnormal blood aluminium levels ${ }^{22,23}$, viral agents $^{24}$, lack of trophic factors ${ }^{25}$, genetic factors ${ }^{4}$ and selective vulnerability of specific neurotransmitter systems ${ }^{26-29}$.

With respect to selective vulnerability of transmitter systems, the marked degeneration of cholinergic neurons in the basal forebrain has received considerable attention ${ }^{26,28,29}$. However, several features of DAT cannot be explained ty the cholinergic hypothesis. Notably, the regional distribution of cortical cholinergic innervation from basal forebrain does not coincide with the cortical areas manifesting the greatest plaque and tangle density ${ }^{30}$. Lesions to the cholinergic basal forebrain neurons in rats and primates have not been shown to produce cortical plaques or tangles. In addition, basal forebrain lesions do not produce the somatostatin ${ }^{31}$ and catecholamine ${ }^{32}$ deficits seen in DAT. Finally, the signs and symptoms of cortical disconnection in DAT are difficult to explain solely on the basis of loss of cortical cholinergic afferents. Thus, while pathology of the ascending cholinergic system is undoubtedly present in DAT, it appears that other neurochemical systems must be involved in the pathophysiology of this disease.

Recently, the excitatory amino acid neurotransmitter, glutamate, has been implicated in learning and memory ${ }^{33}$. A subtype of glutamate receptor, the $N$-methyl-D-aspartate (NMDA) receptor, appears to be particularly important in these processes. In hippocampus, NMDA-receptor antagonists inhibit synaptic transmission in dentate gyrus ${ }^{34}$, block the development of long-term potentiation (LTP) in vitro (a model of memory formation) ${ }^{35}$, and impair spatial discrimination learning and LTP in vivo ${ }^{36}$. NMDAreceptor-mediated excitation has also been observed in cerebral cortex ${ }^{37}$. The NMDA receptor is coupled to a voltage-sensitive cation channel that is gated by $\mathrm{Mg}^{2+}$ (Ref. 38) and blocked by the dissociative anaesthetics ketamine and phencyclidine (PCP) ${ }^{39}$. Both $\mathrm{Mg}^{2+}$ (Ref. 40) and the dissociative anaesthetics inhibit the excitatory actions of NMDA ${ }^{41}$ and the latter block the formation of $L T P^{42}$. Furthermore, anaesthesia induced with dissociative anaesthetics has been reported to produce retrograde and anterograde amnesia of events surrounding the surgical procedure ${ }^{43}$. Thus, impaired glutamate receptor function may be associated with learning and memory impairments.

In this regard, glutamate receptors, particularly the NMDA subtype, have been shown to be decreased in the neocortex of DAT patients compared to agematched controls or Huntington's disease patients ${ }^{20}$. The largest decreases are seen in the outer cortical layers and the $C A 1$ and $C A 2$ regions of the hippocampus. In the cerebral cortex, total glutamate binding is decreased $35-40 \%$, and NMDA receptor density is decreased approximately $60 \%$. Decreases in quisqualate and NMDA receptor subtypes also are observed throughout the $C A 1 / C A 2$ region of the hippocampal formation, although changes in NMDA receptors are the most prominent, approaching $90 \%$ loss in stratum pyramidale ${ }^{44}$. Muscarinic cholinergic, benzodiazepine and high-affinity GABA receptors are not significantly changed in these areas 44,45 , suggesting that the decreased glutamate binding does not simply reflect cortical atrophy. Glutamate binding is also reduced in the subiculum of DAT brains ${ }^{44}$. The subiculum is the primary source of hippocampal efferent fibers ${ }^{46}$ and shows major pathology in $\mathrm{DAT}^{8}$. It is likely that glutamatergic neurotransmission in cortex and hippocampal formation is severely disrupted. The profound loss of glutamate receptors in these regions may provide an explanation for the learning and memory deficits that are prominent in DAT.

Symptoms of cortical disconnection are also common in DAT. These symptoms might be due to the above-mentioned reduction of glutamate receptors as well as loss of afferent input. Corticocortical association fibers arise from presumptive glutamatergic pyramidal cells ${ }^{47,48}$. Their axons terminate primarily in superficial and deep layers of other cortical regions, largely on spines of the apical and basal dendrites of other pyramidal cells ${ }^{49}$. In DAT, cortical glutamate receptor loss is greatest in superficial and deep layers ${ }^{20}$. Senile plaques and neurofibrillary tangles are concentrated in zones of association fiber termination ${ }^{50,51}$ as well as in layers where the cell bodies of these fibers originate ${ }^{51}$.
William F. Maragos, J. Timothy Greenamyre, John B. Penney, Jrand Anne B. Young are at the Department of Neurology and the Neuroscience Program, University of Michigan, Ann Arbor, M1 48104 USA. 


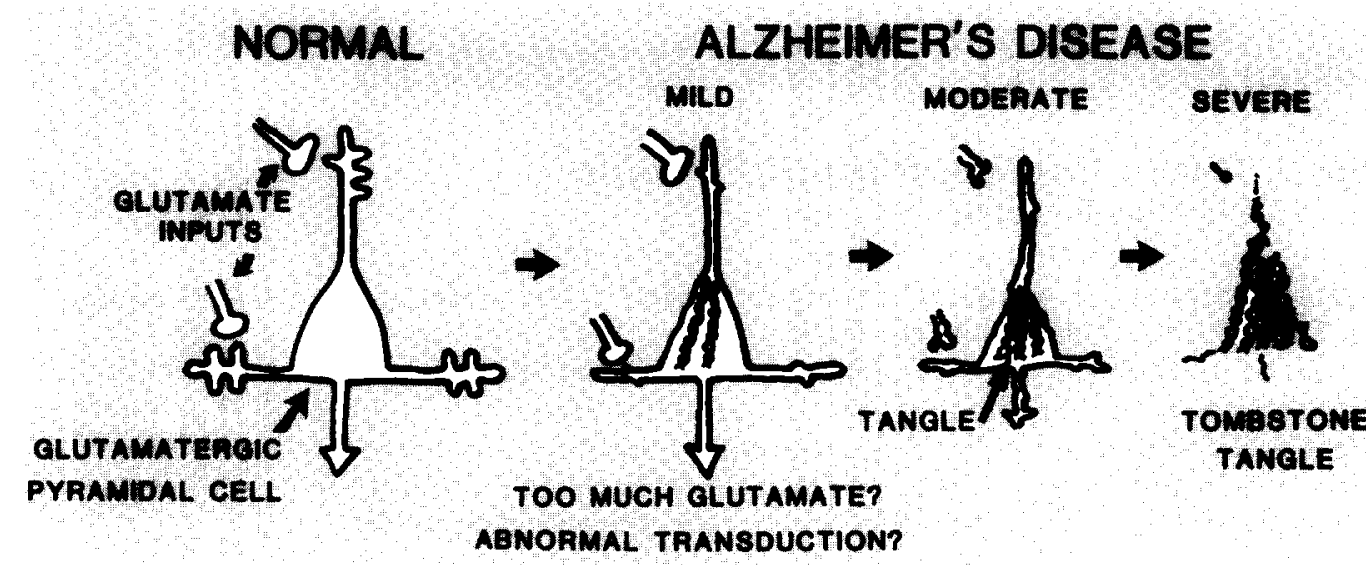

Fig. 1. A schematic representation of the course of neuronal degeneration in DAT. Incoming glutamate fibers terminate on the spines of apical and basilar dendrites of pyramidal neurons. Early in the disease, either due to excess release of glutamate or abnormal receptor transduction, cellular metabolism is altered, spiny processes begin to atrophy and the production of paired helical filaments ensues. Later in the disease, neurofibrillary tangles are formed, which further disrupt cellular metabolism, and cells begin to die. At the final stages of DAT, a significant number of large pyramidal neurons have died, leaving behind nothing but tangles in place of the missing cells. During the course of the disease, the incoming glutamate terminals also degenerate, as their cells of origin are also innervated by other glutamate-utilizing neurons.

Golgi studies of DAT cortex and hippocampus have suggested that there is prominent shrinkage of the terminal dendrites of pyramidal cells, beginning with dendritic spines ${ }^{52,53}$. Recent studies from our laboratory suggest that glutamate-like immunoreactivity is localized in many pyramidal neurons that contain neurofibrillary tangles ${ }^{54}$. Thus, cortical pathology in DAT seems to include abnormalities in the large putative glutamatergic pyramidal neurons, their dendritic spines and their glutamatergic postsynaptic receptors.

Whether the alteration in glutamate receptors in DAT is simply a reflection of cell loss or is causally related to the disease process is an important question. Although the reasons for cellular dysfunction and death in DAT are unknown, glutamatergic dysfunction should be considered as a possible etiologic factor. Glutamate and its excitatory analogs have well-described neurotoxic ('excitotoxic') properties $^{55}$. It has been suggested that glutamate neurotoxicity is associated with neuronal death in Huntington's disease ${ }^{48,56-58}$, olivopontocerebellar atrophy ${ }^{59}$, hypoxia/ischemia ${ }^{60,61}$, hypoglycemia ${ }^{62}$, and status epilepticus ${ }^{60,63}$. Some of these neurotoxic events may be mediated by the NMDA receptor. Antagonists of this receptor inhibit the neuronal degeneration associated with insulin-induced hypoglycemia $^{62}$, and hypoxia/ischemia ${ }^{60}$. Moreover, agonists including NMDA and the endogenous tryptophan metabolite quinolinic acid produce axonsparing lesions similar to those produced by other glutamate analogues ${ }^{64}$

Neuronal degeneration approaches $40-80 \%$ in several regions of the DAT brain ${ }^{65,66}$. The neurons most frequently lost are the large pyramidal neurons; however, the cause of this cell death is unknown. Cell death due to neuronal toxicity could result from excessive synthesis or release of glutamate or a glutamate-like substance, fauity glutamate reuptake, decreased glutamate degradation, or de- creased inhibition of excitatory neurons. Any of these aberrant processes could, early in the disease, increase local levels of glutamate and so initiate a slow, progressive degeneration and eventual death of neurons. Likewise, abnormally enhanced excitatory postsynaptic mechanisms, acting in the presence of normal levels of glutamate, could lead to cell death.

Thus, a plausible scenario for the sequence of events in DAT can be hypothesized (Fig. 1). Early in the disease, glutamatergic inputs to cortical association and hippocampal pyramidal neurons become hyperactive (either by excessive release, faulty re-uptake or altered glutamate receptor sensitivity). The excess of excitation could lead to impaired use of the intracellular energy stores and the inability to maintain the normal neurofilament structure. As the neuron becomes disabled, it would lose the ability to maintain its normal level of membrane hyperpolarization. Voltage-dependent NMDA channels would be more easily activated at less negative membrane potentials and thus the cell would be even more vulnerable to subsequent excitatory input. As part of the toxic process, the cell would not be able to maintain its extensive axonal and dendritic structure and would eventually die. Glutamate receptors would be preferentially lost because they are concentrated on the spinous processes of distal dendrites of pyramidal neurons as opposed to GABA and acetylcholine receptors, which are likely to be located more proximally. A consequence of this hypothesis is that neuronal death would be accelerated early in the disease, but as the disease progressed cell death would occur more slowly.

In support of this hypothesis, recent evidence suggests that glutamate neurotoxicity can produce biochemical changes like those seen in Alzheimer's disease. NMDA applied to the cortex produces retrograde degeneration of cholinergic neurons in the nucleus basalis of rats ${ }^{67}$, suggesting that cortical glutamatergic neurotoxicity might be responsible for the subcortical atrophy previously observed in DAT. Excitotoxic applications in the hippocampus have produced deficits in local somatostatin levels ${ }^{31}$. Furthermore, glutamate has been shown to induce the formation of structures nearly identical to paired helical filaments, the building blocks of neurofibrillary tangles, when added to human spinal cord neurons in culture ${ }^{68}$. Although these studies need to be confirmed in cultures of human cortical neurons using antibodies against paired helical filaments, they lend support to a neurotoxic hypothesis. Finally, in post-mortem studies of patients with advanced DAT, glutamate concentrations ${ }^{69}$ and sodium-dependent aspartate binding ${ }^{70,71}$ are decreased compared to 
age-matched controls, suggesting presynaptic glutamatergic dysfunction. Moreover, in DAT patients, cognitive test scores, which progressively decline during the course of the disease, correlate with the level of glutamate in the cerebrospinal fluid ${ }^{21}$ reflecting the temporal nature of neuronal death.

These data, together with the high degree of correspondence between the anatomical localization of plaques and tangles and the terminals of proposed glutamate pathways, support a possible connection between glutamate and the pathology of DAT. Although the glutamatergic system may be important in the clinical manifestations and pathogenesis of DAT, this hypothesis must be studied in more detail. Whatever the cause of DAT, new strategies aimed at accurate diagnosis and effective treatment of DAT patients must be explored. With the advent of positron emission tomography (PET), it is now possible to image changes in neurotransmitter receptors using labelled ligands ${ }^{72,73}$. Glutamate receptor ligands have the current limitation that they do not easily cross the blood-brain barrier. However, the dissociative anaesthetics, such as ketamine and phencyclidine have ready access to the brain and have been found to inhibit the action of NMDA in a non-competitive fashion in vitro, apparently acting at the associated ion channel ${ }^{39,41}$. We have

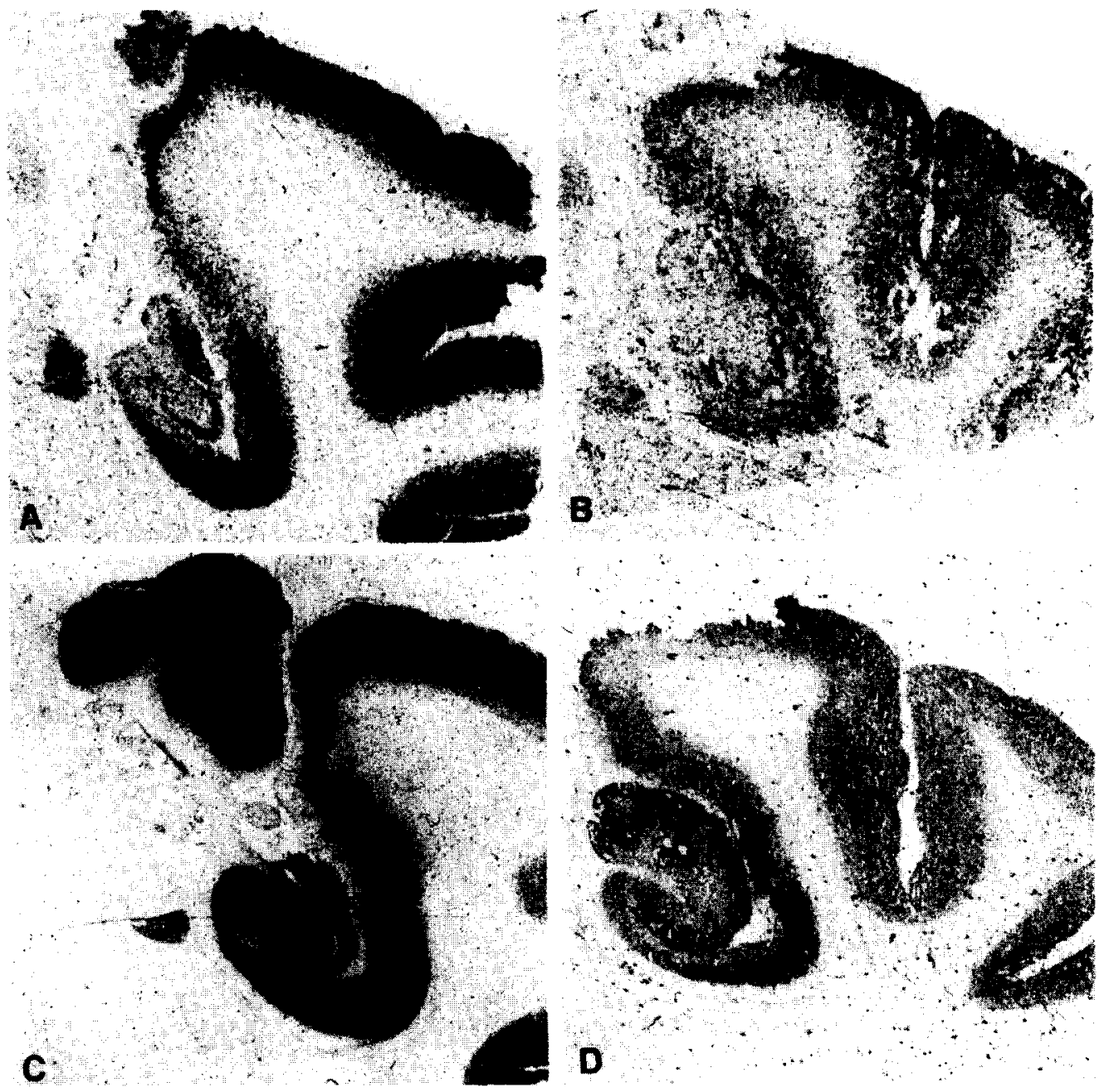

Fig. 2. Autoradiograms of human hippocampal formation obtained from normal and DAT brains. (A) The normal distribution of NMDA receptors labelled with $200 \mathrm{nM}\left[{ }^{3} \mathrm{H}\right] g$ lutamate under NMDA-promoting conditions (in $50 \mathrm{mM}$ Tris-acetate buffer with $1 \mu \mathrm{M}$ quisqualate). (B) NMDA receptor distribution in DAT tissue labelled under the same conditions as (A). Reductions in binding are most prominent in CA1/CA2 and the subiculum. (C) Autoradiogram of dissociative anaesthetic binding sites in another normal case labelled with $40 \mathrm{nM} \mathrm{N}-(1-[2$-thienyl]cyclohexyl)3,4-piperidine $\left({ }^{3}[H] T C P\right)$. (D) $\left[{ }^{3} H\right] T C P$ binding in DAT hippocampal formation. TCP is a non-competitive antagonist of the NMDA receptor. The similar distribution of $\left.{ }^{3} \mathrm{H}\right] T C P$ binding compared to that of NMDA binding in normals and DAT hippocampi suggests that TCP analogs labelled with positron-emitting isotopes might be suitable in-vivo markers for DAT using positron emission tomography.

demonstrated a marked concordance in the distributions of NMDA receptors and the sites to which the dissociative anaesthetics bind ${ }^{74}$ (Fig. 2). Since the NMDA receptor subtype is markedly decreased in DAT cortex and hippocampus, labelled phencyclidine-like drugs or other glutamatergic agonists and antagonists may ultimately prove useful for the early diagnosis of DAT in vivo using PET scanning.

\section{Selected references}

1 McKhann, G., Drachman, D., Folstein, M., Katzman, R., Price, D. and Stadlan, E. M. (1984) Neurology 34, 939-944

2 Khachaturian, Z. S. (1985) Arch. Neurol. 42, 1097-1105

3 Corkin, S., Growdon, J. H., Nissen, M. J., Huff, F. J., Freed, D. M. and Sagar, H. J. (1984) in Alzheimer's Disease.

Advances in Basic Research and Therapies (Wurtman, R. J., Corkin, S. H. and Growdon, J. H., eds), pp. 75-93, Center for Brain Sciences and Metabolism Charitable Trust

4 Constantinidis, J. (1978) in Alzheimer's Disease: Senile Dementia and Related Disorders (Katzman, R., Terry, R. D. and Bick, K. L., eds), pp. 15-25, Raven Press

5 Foster, N. L., Chase, T. N., Patrona, N. J., Gillespie, M. M. and Fedio, P. (1986) Ann. Neurol. 19, 139-143

6 Alzheimer, A. (1907) Allg. Z. Psychiatr. 64, 146-148

7 Terry, R. D., Peck, A., Deteresa, R., Schechter, R. and Horoupian, D. S. (1981) Ann. Neurol. 10, 184-192

8 Hyman, B. T., Van Hoesen, G. W., Damasio, A. R. and Barns, C. L. (1984) Science 225, 1168-1170

9 Coyle, J. T., Price, D. L. and DeLong, M. A. (1983) Science 219, 1184-1190

10 Mash, D. C., Flynn, D. D. and Potter, L. T. (1985) Science 228, 1115-1117

11 Davies, P., Katzman, R. and Terry, R. D. (1980) Nature 288 279-280

12 Beal, M. F., Mazurek, M. F., Tran, V. T., Chattha, G., Bird, E. D. and Martin, J. B. (1985) Science 229, 289-291

13 Mann, D. M. A. and Yates, P. O. (1983) J. Neurol. Neurosurg Psychiatr. 46, 96-98 
14 Perry, E. K., Perry, R. H., Candy, J. M., Fairbain, A. F., Blessed, G. and Tomlinson, B. E. (1984) Neurosci. Lett. 51, 353-358

15 Reynolds, G. P., Arnold, L., Rossor, M. N., Iversen, L. L., Mountioy, C. Q. and Roth, M. (1984) Neurosci. Lett. 44, 47-51

16 Tomlinson, 8. E., Irving, D. and Blessed, G. (1981) J. Neurol. Sci. $49,419-428$

17 Gottfries, C. G. (1984) in Senile Dementia: Outlook for the Future (Wertheimer, J. and Marcois, M., eds), pp. 69-81, Alan R. Liss:

18 Antuono, P. G., Lehman, J., Koller, K. J., Whitehouse, P. J. Clark, A. M., Struble, R. G., Price, D. L. and Coyle, J. T. (1984) Neurology 34 (Suppl. 1), 119

19 Sasaki, H., Muramoto, O., Kanazawa, I., Arai, H., Kosaka, K. and lizuka, R. (1986) Ann. Neurol. 19, 263-269

20 Greenamyre, J. T., Penney, J. B., Young, A. B., D'Amato, C. J. Hicks, S. P. and Shoulson, I. (1985) Science 227, 1496-1499

21 Smith, C. C. T., Bowen, D. M., Francis, P. T., Snowden, J. S. and Neary, D. (1985) J. Neurol. Neurosurg. Psychiatr. 48, 469-471

22 Crapper, D. R., Krishnan, S. S. and Quittkat, S. (1976) Brain 99, 67-80

23 Markesbery, W. R., Ehmann, W. D., Hossain, T. I. M. Alauddin, M. and Goodin, D. T. (1981) Ann. Neurol. 10 , $511-516$

24 Prusiner, S. B. (1984) N. Engl. J. Med. 310, 661-663

25 Appel, S. H. (1984) in Alzheimer's Disease: Advances in Basic Research and Therapies (Wurtman, R. J., Corkin, S. H. and Growdon, J. H., eds), pp. 275-291, Center for Brain Sciences and Metabolism Charitable Trust

26 Davies, P. and Maloney, A. J. R. (1976) Lancet ii, 1403

27 Benton, J. S., Bowen, D. M., Allen, S. J., Haan, E. A., Davison, A. N., Neary, D., Murphy, R. P. and Snowden, J. S. (1982) Lancet ii, 456

28 Whitehouse, P. J., Price, D. L., Clark, A. W., Coyle, J. T. and Delong, M. R. (1981) Ann. Neurol. 10, 122-126

29 McGeer, P. L., McGeer, E. G., Suzuki, J., Dolman, C. E. and Nagai, T. (1984) Neurology 34, 741-745

30 Mesulam, M-M., Volicer, L., Marquis, J. K., Mufson, E. J. and Green, R. C. (1986) Ann. Neurol. 19, 144-151

31 McKinney, M., Davies, P. and Coyle, J. T. (1982) Brain Res. 243, 169-172

32 Johnston, M. V., McKinney, M. and Coyle, J. T. (1979) Proc. Natl Acad. Sci. USA 76, 5392-5396

33 Lynch, G. and Baudry, M. (1984) Science 224, 1057-1063

34 Crunelli, V., Forda, S., Collingridge, G. L. and Kelley, J. S. (1982) Nature 300, 450-452

35 Collingridge, G. L. (1985) Trends Pharmacol. Sci. 6, 407-411 macol. Sci. 6, 407-411

36 Morris, R. G. M., Anderson, E., Lynch, G. and Baudry, M. (1986) Nature 319, 774-776

37 Thomson, A. M., West, D. C. and Lodge, D. (1985) Nature 313. 479-481

38 Nowak, L., Bregestovski, P., Ascher, P., Herbert, A. and Prochiantz, A. (1984) Nature 307, 462-465

39 Honey, C. R., Milijkivic, Z. and MacDonald, J. F. (1985) Neurosci. Lett. 61, 135-139

40 Coan, E. J. and Collingridge, G. L. (1985) Neurosci. Lett. 53 , 21-26

41 Martin, D. and Lodge, D. (1985) Neuropharmacology 24, 999-1003

42 Stringer, J. L., Hackett, J. T. and Guyenet, P. G. (1984) Eur. J. Pharmacol. 98, 381-388

43 Greifenstein, F. E., DeVault, M., Yoshitake, J. and Gajewski, J. E. (1958) Anesth. Analg. 37, 283-294

44 Greenamyre, J. T., Penney, J. B., D'Amato, C. J. and Young, A. B. J. Neurochem. (in press)

45 Nordberg, A., Adolfsson, R., Marcusson, J. and Winblad, B. (1982) in The Aging Brain: Cellular and Molecular Mechanisms (Giacobini, E., ed.), pp. 231-245, Raven Press

46 Swanson, L. W. and Cowan, W. M. (1977) J. Comp. Neurol. $172,49-84$

47 Fonnum, F., Soreide, A., Kvale, I., Walker, J. and Walaas, I. (1981) Adv. Biochem. Psychopharmacol. 28, 29-41

48 Fagg, G. E. and Foster, A. C. (1983) Neuroscience 9, 701-719

49 Lorente, de Nó, R. (1934) J. Psychol. Neurol. 46, 113-177

50 Rogers, J. and Morrison, J. H. (1985) J. Neurosci. 5 , 2801-2808
51 Pearson, R. C. A., Esiri, M. M., Hiorns, R. W., Wilcock, G. K. and Powell, T.P.S. (1985) Proc. Natl Acad. Sci. USA 82 $4531-4534$

52 Scheibel, M. E., Lindsay, R. D., Tomiyasu, U. and Scheibel A. B. (1975) Exp. Neurol. 47, 392-403

53 Mehraein, P., Yamada, M. and Tarnowska-Sziduszko, E. (1975) in Physiology and Pathology of Dendrites (Kreutzberg G. W., ed.), pp. 453-458, Raven Press

54 Maragos, W. F., Debowey, D. L., Reiner, A., Rustioni, A., Penney, J. B. and Young, A. B. (1986) Soc. Neurosci. Abstr. 12 442

55 Fuxe, K., Roberts, P. and Schwarcz, R., eds (1983) Excitotoxins, MacMillan

56 Coyle, J. T. and Schwarcz, R. (1976) Nature 263, 244-246

57 McGeer, E. G. and McGeer, P. L. (1976) Nature 263, 517-519

58 Shoulson, I. (1983) in Excitotoxins (Fuxe, K., Roberts, P. and Schwarcz, R., eds), pp. 343-353, MacMillan

59 Plaitakis, A., Berl, S. and Yahr, M. (1982) Science 216, 193-196

60 Meldrum, B. (1985) Trends Neurosci. 8, 47-48

61 Rothman, S. M. and Olney, J. W. (1986) Ann. Neurol. 19 105-111

62 Wieloch, T. (1985) Science 230, 681-683

63 Sloviter, R. S. and Dempster, D. W. (1985) Brain Res. Bull. 15 $39-60$

64 Schwarcz, R. and Meldrum, B. (1984) Lancet ii, 140-143

65 Mann, D. M. A., Yates, P. O. and Marcyniuk, B. (1986) J. Neurol. Neurosurg. Psychiatr. 49, 310-312

66 Terry, R. D. Peck, A., DeTeresa, R., Schechter, R. and Horoupian, D. S. (1981) Ann. Neurol. 10, 184-192

67 Sofroniew, M. V. and Pearson, R. C. A. (1985) Brain. Res. 339 186-190

68 DeBoni, U. and Crapper-McLachlan, D. R. (1985) J. Neurol. Sci. $68,105-118$

69 Hyman, B. T. Van Hoesen, G. W. and Damasio, A. R. (1986) Soc. Neurosci. Abstr. 12, 944

70 Palmer, A. M., Procter, A. W., Stratmann, G. C. and Bowen D. M. (1986) Neurosci. Lett. 66, 199-204

71 Procter, A. W., Palmer, A. M., Stratmann, G. C. and Bowen, D. M. (1986) N. Engl. J. Med. 314, 1711-1712

72 Wagner, H. N., Jr, Burns, H. D., Dannals, R. F., Wong, D. F. Langstrom, B., Duelfer, T., Frost, J. J., Ravert, H. T., Links J. M., Rosenbloom, S. B., Lukas, S. E., Kramer, A. V. and Kuhar, M. J. (1983) Science 221, 1264-1266

73 Eckelman, W. C., Reba, R. C., Rzeszotarski, W. J., Gibson R. E., Hill, T., Holman, B. L., Budinger, T., Conklin, J. J., Eng. R. and Grissom, M. P. (1984) Science 223, 291-293

74 Maragos, W. F., Chu, D. C. M., Greenamyre, J. T., Penney, J. B. and Young, A. B. (1986) Eur. J. Pharmacol. 123, 173-174

\section{Preliminary Announcement}

The Seventh General Meeting of the International Society for Development Neuroscience entitled Molecular and Clinical Aspects of Developing Neural Systems will be held on 21-24 June 1988 in Jerusalem. Pre-meeting workshops (19-21 June) on specific topics are planned in a beautiful location in Israel. All ISDN members are invited to send suggestions concerning topics and offers to organize workshops, round tables or symposia (at the main meeting or satellite) to the chairman of the Scientific Programme Committee, Dr Ephraim Yavin, Department of Neurobiology, The Weizmann Institute, Rehovot, 76100 Israel, Tel. (972) 8-483653, Telex 361900 WIXIL BITNET: BNYAVIN WEIZMANN. 